\title{
THE PROGNOSIS OF ATRIAL FIBRILLATION FOLLOWING MITRAL VALVOTOMY
}

\author{
BY \\ V. R. BLOOM* \\ From the Department of Medicine, Postgraduate Medical School of London, and Hammersmith Hospital, \\ London, $W .12$ \\ Received August 16, 1962
}

The incidence of sinus rhythm in patients submitted to mitral valvotomy varies between 40 and 60 per cent. In this group atrial fibrillation occurs in the post-operative period in 20 to 50 per cent (Sellors, Bedford, and Somerville, 1953; Wood, $1954 \mathrm{a}$ and b; Dimond and dos Santos, 1954; Heinz and Hultgren, 1957; Ellis, Harken, and Black, 1959; Kittle and Crockett, 1959; Baker and Hancock, 1960; Lowther and Turner, 1962; Black, Lown, and Bartholomay, 1961). The prognosis of atrial fibrillation after mitral valvotomy with and without quinidine therapy is examined in this paper.

Subjects. The cardiac rhythms as confirmed by the electrocardiograms of the 331 patients who underwent their first mitral valvotomy at Hammersmith Hospital between 1951 and 1962 were studied. Of these patients, $151(45 \%)$ were in sinus rhythm, $179(55 \%)$ were in atrial fibrillation, and one was in atrial flutter. Post-operative rhythm changes were always confirmed by the cardiogram.

\section{ResuLts}

Patients in Sinus Rhythm at Mitral Valvotomy. Of the patients who underwent their first valvotomy, 151 were in sinus rhythm and none was given prophylactic quinidine. Forty-six patients developed atrial fibrillation in the post-operative period and 27 of these were treated with digitalis alone; 12 of the $27(44 \%)$ reverted to sinus rhythm spontaneously, 8 within the first two postoperative weeks, 2 at five weeks, 1 at eleven weeks, and 1 at six months.

An attempt to recognize features favouring the spontaneous reversion to normal rhythm revealed that where atrial fibrillation developed in the first post-operative week (19 patients), $12(60 \%)$ reverted to normal rhythm; but where atrial fibrillation developed after the first post-operative week (8 patients), none reverted spontaneously to normal rhythm (Table I). The cardio-thoracic ratio, pre-operative electrocardiographic evidence of right ventricular hypertrophy, other valve lesions,

TABLE I

Six-month Follow-up of 27 Patients who developed Post-operative Atrial FIBRILLATION AND WHO WERE NOT TREATED WITH QUINIDINE

\begin{tabular}{ll|c|c}
\hline & $\begin{array}{c}\text { Onset in first } \\
\text { post-operative week }\end{array}$ & $\begin{array}{c}\text { Onset after first } \\
\text { post-operative week }\end{array}$ \\
\cline { 3 - 4 } Transient atrial fibrillation.. & $\ldots$ & 12 & 0 \\
Established atrial fibrillation & $\cdots$ & 7 & 8 \\
& 19 & 8 \\
\hline
\end{tabular}

* Present address: Central Middlesex Hospital, London, N.W.10. 
calcification of the mitral valve, the final valve size as noted by the surgeon, the presence of mitral regurgitation and its production or increase after valvotomy appeared to have no influence in this respect.

Follow-up of the 12 patients who reverted spontaneously to sinus rhythm revealed that 4 had resumed atrial fibrillation after an average of two and a half years in sinus rhythm. The 8 patients still in sinus rhythm have been followed for an average of two and three-quarter years. All patients were maintained on digitalis and one received maintenance quinidine, but he was one of the four who reverted to atrial fibrillation.

Of the 46 patients who developed atrial fibrillation in the post-operative period, 19 were considered to exhibit features likely to lead to reversion to sinus rhythm with quinidine. These features were the recent onset of atrial fibrillation, age less than 50 years, minimal evidence of cardiac enlargement on the radiograph or in the electrocardiogram, little or no calcification of the mitral valve, and an adequate mitral valvotomy. Two weeks were allowed to elapse lest spontaneous reversion occurred. Phenindione was used to bring the prothrombin time to between 20 and 30 per cent of normal. Following a test dose of $200 \mathrm{mg}$. of quinidine, $400 \mathrm{mg}$. were given every two hours for five doses. Reversion to sinus rhythm was achieved in $13(68 \%)$ patients using an average total dose of $1.4 \mathrm{~g}$. In the 6 patients where normal rhythm was not restored the average dose of quinidine used was $1.9 \mathrm{~g}$., but in 3 the drug was discontinued because of serious side-effects.

The 13 patients who reverted to normal rhythm with quinidine therapy were compared with the 6 in whom reversion could not be achieved, examining the same features that have been previously studied for untreated post-operative atrial fibrillation. Two main differences were revealed. Where reversion was achieved, the average age was 38 years, compared with 46 years where atrial fibrillation persisted; and mitral regurgitation or other valve lesions were twice as common in the unsuccessful group.

Follow-up of the 13 patients in whom sinus rhythm was restored with quinidine revealed that 11 relapsed into atrial fibrillation after an average of two years in sinus rhythm. The 2 patients still in sinus rhythm have been followed for two and three years respectively. The former continued to take quinidine $(200 \mathrm{mg}$.) for three months after discharge from hospital, and the latter took procaine amide ( $250 \mathrm{mg}$. t.d.s.) for six months. Of the 11 patients who have relapsed, 10 received maintenance therapy ( 9 with quinidine and 1 with procaine amide). In all patients the maintenance therapy had been stopped before the onset of atrial fibrillation, but the interval between these two events varied between one day and five and a half years (average interval one and a half years).

Sinus rhythm was restored in 3 of the 5 who were given second courses of quinidine but relapse into atrial fibrillation took place in 2 of the 3 patients. Of these two, one received a thirp course of quinidine which did not restore sinus rhythm, and in the other the second course resulted in a period of four years in sinus rhythm although the initial period in sinus rhythm in this patient had been only ten days.

The cardiac rhythms at the end of each year in patients observed for four years are shown in Table II. In compiling this table no account has been taken of the results of second courses of

TABLE II

Late Follow-up of Patients who deVeloped Post-operative Atrial Fibrillation

\begin{tabular}{|c|c|c|c|c|}
\hline & $\begin{array}{l}\text { At } 2 \text { years } \\
\text { (No.) }\end{array}$ & $\begin{array}{l}\text { At } 3 \text { years } \\
\text { (No.) }\end{array}$ & $\begin{array}{l}\text { At } 4 \text { years } \\
\text { (No.) }\end{array}$ & Remarks \\
\hline $\begin{array}{l}\text { Sinus rhythm maintained } \\
\text { Atrial fibrillation resumed }\end{array}$ & $\begin{array}{l}6 \\
0\end{array}$ & $\begin{array}{l}5 \\
1\end{array}$ & $\begin{array}{ll}2 & \\
4 & \end{array}$ & Spontaneous reversion to sinus rhythm \\
\hline $\begin{array}{l}\text { Sinus rhythm maintained } \\
\text { Atrial fibrillation resumed }\end{array}$ & $\begin{array}{l}7 \\
1\end{array}$ & $\begin{array}{l}3 \\
5\end{array}$ & $\begin{array}{ll}2 & \\
6 & \}\end{array}$ & Quinidine conversion to sinus rhythm \\
\hline
\end{tabular}


quinidine. It has been presumed that where a second course of quinidine restored sinus rhythm, atrial fibrillation would have persisted had it not been given.

One of the patients treated with quinidine for post-operative atrial fibrillation died suddenly and unexpectedly while on maintenance quinidine.

Patients in Atrial Fibrillation at Mitral Valvotomy. Of the 179 patients who underwent mitral valvotomy in atrial fibrillation, there was only one instance of spontaneous reversion to sinus rhythm. In this case reversion occurred five years after mitral valvotomy. Such an occurrence has not previously been reported.

Twenty-seven of 179 patients were selected for quinidine therapy. This was begun between the second and fifth weeks after operation, and was successful in restoring sinus rhythm in 6 patients $(22 \%)$ using an average dose of $2.8 \mathrm{~g}$., compared with $2 \cdot 7 \mathrm{~g}$. in the failures.

The 6 patients who were converted with quinidine were compared with the 21 where conversion was not achieved, on the basis of the features already mentioned. No difference between the two groups that might anticipate success with quinidine was apparent, nor did these patients differ in any of the features studied from those who developed atrial fibrillation in the postoperative period and who were treated with quinidine.

Follow-up of the 6 patients who were converted to sinus rhythm with quinidine showed that 5 had relapsed after six months. Two of these were on maintenance therapy at the time of relapse. The only good long-term result was in a patient in whom atrial fibrillation had been precipitated just before mitral valvotomy by cardiac catheterization: this patient remained in sinus rhythm for one year but had relapsed into atrial fibrillation when seen after two years. Second attempts at conversion were made in 3 patients and were successful in 2: these patients remained in sinus rhythm for four days and two and three-quarter years respectively. In the former three subsequent attempts at conversion were made, one of which was successful, leading to a further three weeks in sinus rhythm.

One patient with pre-operative atrial fibrillation who was treated with quinidine died suddenly and circumstantial evidence that death was due to quinidine was very strong.

Embolism. No instances of embolism were seen following mitral valvotomy in either those who reverted to sinus rhythm spontaneously (12 patients) or those who reverted with quinidine (19 patients), or in either group when relapse into atrial fibrillation took place. Seven patients who were thought to be at risk from embolism were given anticoagulants at the time of valvotomy and anticoagulants were also given during quinidine therapy.

\section{Discussion}

Of 331 patients who underwent mitral valvotomy 45 per cent were in sinus rhythm. Of these 30 per cent developed atrial fibrillation in the post-operative period: 70 per cent, therefore, were in atrial fibrillation either temporarily or permanently after valvotomy. These figures are in broad agreement with several reported series (Sellors et al., 1953; Wood, 1954 a and b; Dimond and dos Santos, 1954; Heinz and Hultgren, 1957; Ellis et al., 1959; Kittle and Crockett, 1959; Baker and Hancock, 1960; Black et al., 1961; Lowther and Turner, 1962).

Where atrial fibrillation developed in the post-operative period, there was a strong tendency for spontaneous reversion to occur, related to the time of onset of the arrhythmia. Reversion occurred in 60 per cent of patients where atrial fibrillation developed in the first post-operative week, but in none of those where the onset was later. Of the patients who reverted spontaneously 66 per cent did so in the first post-operative fortnight; of those remaining in atrial fibrillation after the first post-operative fortnight (having developed atrial fibrillation in the first post-operative week) 33 per cent subsequently reverted to sinus rhythm. Six of the cases of post-operative atrial fibrillation have been followed up for four years and two are still in sinus rhythm.

Quinidine was successful in restoring sinus rhythm in 68 per cent of patients with post-operative $2 \mathrm{R}$ 
atrial fibrillation persisting beyond the second post-operative week. Although there was no statistical difference from the results of spontaneous reversion $(p=0 \cdot 2-0 \cdot 1)$, reversion was achieved in 4 patients who developed atrial fibrillation after the first week and in whom, therefore, spontaneous reversion would not have been expected. Sellors et al. (1953) and Heinz and Hultgren (1957) reported a success rate of 70 per cent for patients treated after the first post-operative fortnight. Kittle and Crockett (1959) reported conversion in 84 per cent of their cases, but they gave quinidine on the tenth day. However, Fraser and Turner (1955) had success in 95 per cent of their cases treated after the first post-operative fortnight. It therefore seems that quinidine has an advantage over the results of spontaneous conversion in achieving sinus rhythm though all series have probably included some cases where late spontaneous conversion might have occurred.

In the present series, 9 of the 13 patients with post-operative atrial fibrillation, who reverted to sinus rhythm with quinidine, had developed atrial fibrillation in the first post-operative week. Untreated, 3 of these might have been expected to revert to sinus rhythm spontaneously. Disregarding these 3 , the success rate for quinidine would have been 61 per cent (10 in 16 cases). This figure corresponds very closely to the mean figure of 62 per cent obtained from the figures of Burwell and Dieuaide (1923), Hay (1924), and Holzman and Brown (1951), who analysed the results of quinidine therapy in over 1300 patients with atrial fibrillation.

Fraser and Turner (1955) have argued that there are two relevant factors in the production of atrial fibrillation following mitral valvotomy: trauma and the rheumatic process. If this is correct and the effects of trauma are reversible, the success rate with quinidine, after excluding cases in which spontaneous reversion might be expected, should approximate to that obtained in patients who have not undergone operation. That this was so in the present series substantially supports the view of Fraser and Turner, and indicates that the post-operative period offers an apparent rather than a real advantage for quinidine therapy. Where trauma is the major factor in precipitating atrial fibrillation spontaneous reversion might be expected, but where the continuation of the rheumatic process is the major factor, the opportunities for success with quinidine are the same as at any other time.

The relapse rate was greater in those converted to sinus rhythm with quinidine than those who reverted spontaneously. On the basis of the four-year follow-up of patients not on maintenance therapy, the number of patients in sinus rhythm would be the same whether quinidine had been used or not. Still less benefit was gained from the use of quinidine in patients who underwent mitral valvotomy in atrial fibrillation, even though the onset of the fibrillation was recent in many, and the other features studied might have been expected to predispose to a successful outcome. In fact, success was achieved in only $6(22 \%)$ patients, of whom 5 had relapsed into fibrillation within six months. The only success was in a patient in whom atrial fibrillation had been precipitated by cardiac catheterization just before operation. Thus, the only indication for quinidine appears to be in patients who develop atrial fibrillation in the post-operative period and here the advantage over the results of spontaneous reversion is small and does not last very long.

Hæmodynamic studies before and after conversion from atrial fibrillation to sinus rhythm with quinidine by Kerkhof (1936), Kory and Meneely (1951), Hecht, Osher, and Samuels (1951), Hansen, McClendon, and Kinsman (1952), Wetherbee, Brown, and Holzman (1952), Broch and Müller (1957), and Selzer (1960) have all shown the advantages of sinus rhythm, but Selzer has questioned the extent to which such differences can affect the patients symptomatically. Hecht and Lange (1956) have stressed the advantage of controlled atrial fibrillation over less well-controlled sinus tachycardia. They draw attention to the dangers of quinidine intoxication, the possibility of dislodging recent thrombi with the onset of co-ordinate contraction of the atria and the poor long-term results. In the present series resumption of atrial fibrillation has been accompanied by clinical deterioration in 7 of 15 patients, 5 of whom were not taking digitalis. All the remainder were on digitalis and the majority of these were unaware of the change of rhythm.

The risk of sudden death from quinidine has been stressed by numerous authors. Burwell and Dieuaide (1923) reviewed 10 deaths in 143 patients, and Hay (1924) attributed sudden death to 
quinidine in 8 of 286 cases. Askey (1946) records 21 deaths in 839 patients treated in the next two decades. These figures indicate a 3 per cent mortality, but more recently Sokolow and Ball (1956) and Yount, Rosenblum, and McMillan (1952) have reported a mortality as low as 1 per cent. Askey (1946) has pointed out that sudden death is always a hazard in rheumatic heart disease, and that the main risk of quinidine is its use in congestive cardiac failure. Sokolow and Ball (1956) showed that the incidence of myocardial toxicity increased rapidly with serum quinidine levels over $8 \mu \mathrm{g}$. $/ \mathrm{ml}$. but quoted a personal communication of Sampson who observed paroxysmal ventricular fibrillation with serum quinidine levels below $3.5 \mu \mathrm{g} . / \mathrm{ml}$. in patients with mitral stenosis. Finnegan and Trounce (1954) reported one fatal and two severe reactions after moderate doses of quinidine $(1.4 \mathrm{~g}$., $1.2 \mathrm{~g}$.). In the present series, one fatality occurred after $0.9 \mathrm{~g}$. and the other on a daily maintenance dose of $0.8 \mathrm{~g}$. A similar fatality after mitral valvotomy has been reported by Fraser and Turner (1955). It is likely that quinidine which acts by depressing nodal and conduction tissue causes ventricular fibrillation and cardiac arrest in some patients with doses that would be harmless to the majority. There seems to be no way of predicting where this will occur, and it is doubtful whether the conventional test dose gives much help in this respect.

Finnegan and Trounce (1954) have shown that the most valuable drug for reviving the animal heart depressed by quinidine is intracardiac adrenaline, but this was not effective in one of the patients reported here.

Hay (1924) said that little or nothing is to be gained from the use of quinidine in badly damaged hearts with old-standing valvular disease. The present work seems to indicate that the advent of mitral valvotomy has done nothing to refute this view. Furthermore, as Lowther and Turner (1962) have pointed out, it has yet to be shown that atrial fibrillation has an adverse influence on the long-term results of mitral valvotomy.

\section{SUMMARY}

Of 331 patients $(45 \%)$ who underwent valvotomy, 151 were in sinus rhythm.

Atrial fibrillation developed in $46(30 \%)$ of the 151 patients in sinus rhythm during or shortly after valvotomy. Twelve $(44 \%)$ of 27 such patients reverted to sinus rhythm spontaneously, but 4 of the 12 relapsed into atrial fibrillation after an average period of follow-up of two and a half years. Of 6 patients who have been followed for four years, 2 are still in sinus rhythm.

The most important factor in determining whether spontaneous reversion would take place was the time of onset of the atrial fibrillation. Where the onset was in the first post-operative week there was a 60 per cent chance of spontaneous reversion. Where the onset was later, spontaneous reversion did not take place.

Quinidine restored sinus rhythm in $13(68 \%)$ of 19 cases of post-operative atrial fibrillation who had not reverted spontaneously after two weeks. The average dose required was $1.4 \mathrm{~g}$. Eleven $(85 \%)$ of the 13 cases relapsed into atrial fibrillation after an average follow-up for two years. Of 8 patients who have been followed for four years, $2(25 \%)$ are still in sinus rhythm.

Quinidine had a slight advantage over the results of spontaneous reversion in those developing atrial fibrillation post-operatively, but this difference was not statistically significant $(p=0 \cdot 2-0 \cdot 1)$. The relapse rate was greater in the group treated with quinidine so that four years after operation this advantage was lost.

Of 179 patients who underwent mitral valvotomy in atrial fibrillation, only 1 reverted to sinus rhythm spontaneously. Quinidine restored sinus rhythm in $6(22 \%)$ of 27 cases of pre-operative atrial fibrillation: the average dose required was $2 \cdot 8 \mathrm{~g} . ; 5(80 \%)$ of the 6 had relapsed into atrial fibrillation six months later.

There were 2 unexpected deaths in the 46 patients during treatment with quinidine.

My thanks are due to Mr. W. P. Cleland and Mr. H. H. Bentall for permission to study their cases, and to Dr. J. F. Goodwin for helpful advice and criticism. 


\section{REFERENCES}

Askey, J. M. (1946). Quinidine in the treatment of auricular fibrillation in association with congestive failure. Ann. intern. Med., 24, 371.

Baker, C., and Hancock, W. E. (1960). Deterioration after mitral valvotomy. Brit. Heart J., $22,281$.

Black, H., Lown, B., and Bartholomay, A. F. (1961). The value of quinidine in the prevention of atrial fibrillation after mitral valvuloplasty. Circulation, 23, 519.

Broch, O. J., and Müller, O. (1957). Hæmodynamic studies during auricular fibrillation and after restoration of sinus rhythm. Brit. Heart J., 19, 222.

Burwell, C. S., and Dieuaide, F. R. (1923). Clinical experience with quinidin. Arch. intern. Med., 31, 518.

Dimond, E. G., and dos Santos, E. M. (1954). Complications following mitral commissurotomy with special reference to auricular fibrillation. J. Kans. med. Soc., 55, 120.

Ellis, L. B., Harken, D. E., and Black H. (1959). A clinical study of 1,000 consecutive cases of mitral stenosis two to nine years after mitral valvuloplasty. Circulation, 19, 803.

Finnegan, T. R. L., and Trounce, J. R. (1954). Depression of the heart by quinidine and its treatment. Brit. Heart J., 16, 341.

Fraser, H. R. L., and Turner, R. W. D. (1955). Auricular fibrillation: with special reference to rheumatic heart disease. Brit. med. J., 2, 1414.

Hansen, W. R., McClendon, R. L., and Kinsman, J. M. (1952). Auricular fibrillation: hemodynamic studies before and after conversion with quinidine. Amer. Heart J., 44, 499.

Hay, J. (1924). The action of quinidine in the treatment of heart disease. Lancet, $2,543$.

Hecht, H. H., and Lange R. L. (1956). The hæmodynamic consequence of atrial fibrillation. Mod. Conc. cardiovasc. Dis., 25, 351.

- Osher, W. J., and Samuels, A. J. (1951). Cardiovascular adjustments in subjects with organic heart disease before and after conversion of atrial fibrillation to normal sinus rhythm. J. clin. Invest., $30,647$.

Heinz, R., and Hultgren, H. (1957). Atrial fibrillation following mitral valvulotomy. Arch. intern. Med., 99, 896.

Holzman, D., and Brown, M. G. (1951). The use of quinidine in established auricular fibrillation and flutter. Amer. J. med. Sci., $222,644$.

Kerkhof, A. C. (1936). Minute volume determinations in mitral stenosis during auricular fibrillation and after restoration of normal rhythm. Amer. Heart J., 11, 206.

Kittle, C. F., and Crockett, J. E. (1959). The etiology and prevention of atrial fibrillation after mitral valvotomy. J. thorac. cardiovasc. Surg., 38, 353.

Kory, R. C., and Meneely, G. R. (1951). Cardiac output in auricular fibrillation with observations on the effects of conversion to normal sinus rhythm. J. clin. Invest., 30, 653 .

Lowther, C. P., and Turner, R. W. D. (1962). Deterioration after mitral valvotomy. Brit. med.J., 1, 1027 and 1102.

Sellors, T. H., Bedford, D. E., and Somerville, W. (1953). Valvotomy in the treatment of mitral stenosis. Brit. med. J., 2, 1059.

Selzer, A. (1960). Effects of atrial fibrillation upon the circulation in patients with mitral stenosis. Amer. Heart J., $59,519$.

Sokolow, M., and Ball, R. E. (1956). Factors influencing conversion of chronic atrial fibrillation with special reference to serum quinidine concentration. Circulation, 14, 568.

Wetherbee, D. G., Brown, M. G., and Holzman, D. (1952). Ventricular rate response following exercise during auricular fibrillation and after conversion to normal sinus rhythm. Amer. J. med. Sci., 223, 667.

Wood, P. (1954a). An appreciation of mitral stenosis. Part I. Clinical features. Brit. med.J., $1,1051$.

(1954b). An appreciation of mitral stenosis. Part II. Investigations and results. Brit. med. J., 1, 1113.

Yount, E. H., Rosenblum, M., and McMillan, R. L. (1952). Use of quinidine in the treatment of chronic auricular fibrillation. Arch. intern. Med., 89, 63. 